\title{
DERECHO CONSTITUCIONAL COMPARADO EN EL CONTEXTO DE LA INTEGRACIÓN SUPRANACIONAL Y LA GLOBALIZACIÓN ${ }^{1}$
}

\author{
MARÍA SALVADOR MARTÍNEZ \\ Profesora Contratada-Doctora \\ UNED
}

\author{
SUMARIO \\ I. Sobre el derecho comparado \\ II. Origen y desarrollo del derecho constitu- \\ cional comparado \\ III. El derecho constitucional comparado a \\ principios del s. XXI \\ IV. Actuales influencias recíprocas entre di- \\ ferentes culturas constitucionales
}

Este trabajo tiene por objeto realizar un breve análisis de la actual situación del derecho constitucional comparado, destacando el desarrollo que ha experimentado como consecuencia de los procesos de internacionalización e integración supranacional, y resaltando una de sus principales características actuales, cual es la intensificación de las influencias recíprocas entre diferentes sistemas jurídicos y entre distintas culturas constitucionales.

\section{SOBRE EL DERECHO COMPARADO}

Si bien estas líneas tienen por objeto el análisis de las características actuales del derecho constitucional comparado, es preciso comenzar realizando

1 El presente trabajo se presentó como comunicación a las Jornadas sobre Orientación y Método del Derecho Constitucional organizadas por la revista Teoría y Realidad Constitucional el 16 de noviembre de 2007 
algunas consideraciones de carácter general sobre la naturaleza del derecho comparado, su objeto y los elementos definitorios de su metodología.

Así, en primer lugar, desde el punto de vista de su naturaleza hay que referirse al debate sobre el carácter autónomo o dependiente del derecho comparado, sobre si éste debe considerarse un método auxiliar o una ciencia independiente, pues se trata del principal debate que ha acompañado a esta disciplina desde su origen y constituye uno de los elementos de discusión sobre los que, aún hoy, no existe una posición unánime. ${ }^{2}$

En este sentido, de una parte, hay quien considera que el derecho comparado es esencialmente un método de investigación, de estudio, que desempeña una labor auxiliar en diversas disciplinas científicas, pero que no posee una entidad propia, sino que sirve al objetivo de la disciplina a la que auxilia, de tal modo que los resultados que se obtienen del análisis comparado se suman a los argumentos que aporta dicha disciplina. ${ }^{3}$ De otra parte, sin embargo, hay quien entiende que el derecho comparado no es un simple método auxiliar, sino una ciencia autónoma, con suficientes características específicas y principios metodológicos propios que permiten diferenciarla de las restantes disciplinas jurídicas, y que persigue ciertas finalidades también propias, que se especifican en cada investigación concreta, y que, de acuerdo con los teóricos de esta nueva ciencia, pueden responder a alguno de los siguientes objetivos: buscar la mejor solución a un determinado problema jurídico, determinar las relaciones causales entre ellos, o poner de manifiesto la evolución histórica de un problema jurídico concreto. ${ }^{4}$ Finalmente, no falta quien considera que, a la vista de lo dicho, el derecho comparado tiene una doble naturaleza, es, al mismo tiempo, ciencia y método, ya que "la ciencia no es, a la postre, sino métodom. ${ }^{5}$ Efectivamente, una ciencia se diferencia de otra por el método con el que analiza un determinado objeto, de tal modo que para afirmar que estamos ante una nueva ciencia es preciso que ésta utilice un método diferente y propio. Por eso, lo que realmente hay que determinar es si el método comparado es esencialmente diferente del jurídico y, por lo tanto, hay que considerar al de-

2 Como referencia del inicio de estos debates debemos citar el trabajo clásico de Blagojevic, B., Le droit comparé-méthode ou science, publicación extraordinaria de la Revue internationale du droit comparé, $\mathrm{n}^{\circ} 4,1953$.

3 Especialmente desde la obra de GuTTERIDGe, H. C., An introduction to the comparative method of legal study and research, Cambridge University Press, Cambridge, 1949 ( $2^{\mathrm{a}}$ ed.). También DE Cruz, P., A modern approach to comparative law, Kluwer, Deventer, 1993.

4 Es la tesis mantenida en Italia por autores como Rotondi y más recientemente Pizzorusso, Biscaretti di Rufia y Vergottini (RoTONDI, Dogmatica e diritto comparato, Cedam, Padua, 1930, págs. 17 a 19; PIzzorusso, Corso di diritto comparato, Giuffrè, Milan, 1983, págs. 80-81; BISCARETTI DI RUFIA, Introducción al derecho constitucional comparado, Fondo de Cultura Económica, México, 1975, pág. 13; De Vergottini, Derecho Constitucional Comparado, Espasa Calpe, Madrid, 1983, págs. 84 y ss.). Es también la visión de los primeros teóricos de la comparación como Saleillles, Rabel, Rheinstein o Hall.

5 DE la SierRa, S., Una metodología para el derecho comparado europeo. Derecho público comparado y derecho administrativo europeo, Thomson-Civitas, Madrid, 2004, pág. 25, citando a Nieto, A./ Gordillo, A., Las limitaciones del conocimiento jurídico, Trotta, Madrid, 2003. 
recho comparado como una ciencia autónoma de la ciencia jurídica, o si, por el contrario, se entiende que el método comparado es un método jurídico y, con ello, que el derecho comparado es ciencia jurídica, lo cual no impide reconocer la relevancia que le corresponde como especialidad metodológica de la ciencia jurídica ni elaborar una teoría general del derecho comparado a partir de todos los elementos metodológicos específicos que éste aporta.

En la práctica, la consideración del derecho comparado como ciencia autónoma no excluye ni es incompatible con su consideración como método auxiliar a otras ciencias. Por ello, al margen de las contribuciones doctrinales dirigidas a la construcción de una teoría general del derecho comparado (función, objeto, método, ciencias auxiliares...), las diferentes disciplinas jurídicas, tanto de derecho público como de derecho privado, han utilizado y utilizan el recurso a la comparación como medio de lograr sus propios objetivos.

En segundo lugar, desde el punto de vista del objeto del derecho comparado, debemos referirnos a la distinción entre derecho comparado y derecho extranjero. Los especialistas en la materia ponen especial interés en distinguir entre ambas categorías; consideran que el estudio del derecho extranjero, el análisis de otro u otros ordenamientos jurídicos distintos del propio, constituye metodológicamente un paso previo al análisis de derecho comparado en sentido estricto, pero advierten que un estudio de derecho extranjero, por sí mismo, no puede considerase un trabajo de derecho comparado, ya que éste último exige, además, la utilización de los criterios metodológicos y la orientación a una de las finalidades que definen la ciencia del derecho comparado. Es decir, comparar exige un objeto de referencia distinto del propio y la comparación implica el estudio del derecho extranjero, aunque no se agote en él. De acuerdo con esto, un trabajo de derecho comparado, en sentido estricto, exige el análisis de más de un ordenamiento, el examen conjunto de todos ellos y la operación lógica de confrontación de la cual se extraen las conclusiones correspondientes. ${ }^{6}$

En tercer lugar, y por lo que se refiere a los elementos metodológicos que definen al derecho comparado, sin ánimo de exhaustividad, se pueden destacar los siguientes:

1. Para empezar, puesto que nos movemos en el campo de las disciplinas jurídicas, es preciso recordar que el método aplicable no puede ser otro que "un método jurídico", aunque a él se añada el elemento de la comparación de ordenamientos o institutos, con sus correspondientes reglas específicas. ${ }^{7}$

6 Esta distinción se encuentra en todos los trabajos sobre la ciencia del derecho comparado. En nuestra materia, entre otros, se puede citar a Pegoraro, L., "El método en el Derecho Constitucional: la perspectiva desde el Derecho comparado", en Revista de Estudios Políticos, n 112, 2001, págs. 9 y ss. (pág. 21); y de Vergottini, G., Diritto costituzionale comparato, Cedam, Padua, 2004 (6 ed.), págs. 25 y 26.

7 BiscaretTI Di Rufia, P., Introducción al derecho constitucional comparado, op. cit., págs. 19 y ss. 
2. A la hora de iniciar un estudio de derecho comparado, la primera decisión determinante es la relativa a la elección de los elementos que van a compararse, para lo cual es fundamental optar por elementos que sean "comparables", es decir, que no sean idénticos, ni que sean completamente diferentes, sino que sean similares, que muestren suficientes características definitorias que permitan su comparación y, sobre todo, que hagan posible la obtención de resultados útiles. Esta exigencia se predica tanto de los ordenamientos como de las instituciones concretas objeto de análisis. ${ }^{8}$ En este sentido, no existe mayor problema cuando se trata de comparar una institución tradicional, bien conocida, con un régimen jurídico perfectamente definido, incluso con un nombre común por encima de las fronteras, como puede ser el caso si se elige como objeto de estudio el parlamento, el gobierno o los partidos políticos. No ocurre lo mismo, sin embargo, si se pretende analizar instituciones de reciente creación o figuras cuyo régimen jurídico no está suficientemente delimitado, ya que, en ese caso, es necesaria una labor previa de definición y deslinde conceptual.

Así pues, el elemento objeto de comparación determina la forma de trabajo. A ello responde la distinción clásica entre "macrocomparación", que pretende un análisis general de las características de un determinado número de ordenamientos, y "microcomparación", que pretende examinar el régimen de una institución jurídica concreta en diversos ordenamientos, así como el sometimiento de cada una de estas formas de comparación a diferentes reglas metodológicas. ${ }^{9}$

3. Entre los principios esenciales que deben guiar cualquier análisis de derecho comparado destaca el que impone analizar el objeto de estudio en su contexto jurídico-político, y teniendo en cuenta la cultura jurídica y política correspondiente. ${ }^{10}$ En el ámbito de nuestra disciplina, cualquier institución o forma concreta de organización sólo puede valorarse en relación con el contexto en el que opera, y, puesto que los contextos de dichas instituciones pueden presentar características históricas y constitucionales claramente distintas, es preciso ser consciente de las diferencias entre dichos contextos; diferencias, por ejemplo, en cuanto al sistema jurídico, los principios estructurales del Estado, la forma de gobierno o la forma de organización territorial. Las soluciones de un ordenamiento jurídico pueden ser útiles para otro siempre que se sometan a un análisis de ese tipo, pues, como se ha demostrado ya en algu-

8 Entre otros, de Vergottini, G., Diritto costituzionale comparato, op. cit., págs. 70 a 75.

9 Sobre la distinción entre estos dos tipos de estudio comparado debemos remitir a ConsTAntinesco, L. J., Traité de droit comparé, LGDJ, Paris, 1972-1973.

10 En este sentido hay que mencionar los conocidos trabajos sobre la cultura de HäBERLE, P.; además, "Gibt es eine europäische Öffentlichkeit?, en Schriften der Juristischen Gesellschaft zu Berlin, Walter de Gruyter, Berlin, 2000; y Rechtsvergleichung im Kraftfeld des Verfassungsstaates. Methoden und Inhalte, Kleinstaaten und Entwickungsländer, Duncker \& Humblot, Berlin, 1992. 
na ocasión, la importación directa de soluciones sin tener en cuenta el contexto puede llevar a consecuencias contrarias a las buscadas.

4. El método comparado consiste, como se sabe, en el análisis y comparación entre ordenamientos diferentes, o instituciones de ordenamientos diferentes, para llegar a determinadas conclusiones. Pues bien, esa labor se apoya de forma determinante en las clasificaciones y agrupaciones de sistemas jurídicos que se han elaborado previamente atendiendo a sus similares características. Por eso, una de las finalidades de la ciencia del derecho comparado consiste en la elaboración de esquemas de referencia, modelos teóricos y categorías, que se deducen del estudio comparado de los diferentes ordenamientos, y que, posteriormente, son los que se utilizan, tanto para comprender mejor los correspondientes sistemas e instituciones, como para los trabajos concretos de derecho comparado que se realicen en las diferentes disciplinas jurídicas. ${ }^{11}$

5. Por último, debemos referirnos al que seguramente es el mayor escollo que debe superar el investigador, el problema lingüístico, tanto para poder acceder a las fuentes extranjeras (normativas, jurisprudenciales y doctrinales), como para transmitir el conocimiento obtenido de las mismas, "traduciendo" ese derecho extranjero al "lenguaje jurídico" del propio ordenamiento. Y no sólo porque todo ello exige un conocimiento suficiente del idioma extranjero, sino también del "lenguaje jurídico" de ese ordenamiento extranjero, de las características del mismo, del estado de su doctrina, de su contexto jurídico-político y de su cultura jurídica. ${ }^{12}$

\section{ORIGEN Y EVOLUCIÓN DEL DERECHO CONSTITUCIONAL COMPARADO}

El derecho comparado, como método auxiliar, es común a todas las ramas de la ciencia jurídica (el derecho constitucional, el derecho procesal, el derecho civil...), que se diferencian entre sí por el objeto de estudio, pero que comparten un mismo método, el método jurídico. Así es, el interés por las regulaciones de ordenamientos distintos del propio, y el análisis tanto de las decisiones jurisprudenciales extranjeras, como de las fórmulas seguidas por los legisladores de otros países en la resolución de problemas, han sido comunes a todas las disciplinas jurídicas. No sólo a partir de consideraciones de lege ferenda, relativas a la eventual reforma del propio ordenamiento, sino también desde una

11 Véase la obra clásica de DAvid, R., Les Grands Systémes de Droit Contemporains, Dalloz, Paris, 1950, en la que se consolida el concepto de "familias legales", aquellas en las que se agrupan los diferentes sistemas jurídicos según sus características.

12 Entre otros, DE LA SierRa, S., Una metodología para el derecho comparado europeo, op., cit., págs. 102 y ss. 
perspectiva de lege lata, por cuanto el examen de ejemplos extranjeros puede conducir a una más precisa comprensión e interpretación de las normas e instituciones propias. En materia constitucional, por ejemplo, malamente se puede dar por zanjado el tema de la relación entre la ley y el reglamento sin conocer el derecho constitucional francés, o las consideraciones sobre el valor de las sentencias interpretativas sin haber acudido a la doctrina italiana, o la consideración de los problemas que suscita el art. 155 de la Constitución Española sin haber considerado el "modelo alemán".

Este recurso al estudio de modelos extranjeros y a la comparación ha sido también constante a lo largo del tiempo. Los estudiosos de la ciencia del derecho comparado sitúan los precedentes más antiguos en la época clásica, aunque el método comparado no se desarrolló plenamente hasta que no lo hizo la moderna ciencia del derecho. ${ }^{13}$ Así, en materia constitucional, por ejemplo, desde la época clásica, ${ }^{14}$ los pensadores y académicos de todos los tiempos han analizado y comparado diferentes sistemas políticos para determinar cuál era el mejor de ellos, aunque la comparación constitucional, en sentido estricto, no se inicia hasta los episodios revolucionarios de finales del siglo XVIII y la formación de los Estados constitucionales. Desde aquel primer constitucionalismo, en el que Francia y Estados Unidos se convirtieron en referentes indiscutibles por haber triunfado allí las revoluciones burguesas, la circulación de las ideas de las elites progresistas, el estudio de los referentes extranjeros y el mimetismo en la organización jurídico-política han acompañado al desarrollo de los Estados constitucionales y del derecho constitucional.

Más atención requieren, sin embargo, el origen y la evolución de la ciencia del derecho comparado, es decir, de la disciplina científica definida y desarrollada por los académicos. Dejando a un lado precedentes anteriores, la moderna ciencia del derecho comparado se gestó a lo largo del siglo xIX, sobre todo en Alemania y Francia, a partir de diversos elementos: primero, los movimientos de codificación y unificación del derecho, ya que las correspondientes comisiones codificadoras nacionales, en su trabajo, prestaban mucha atención a las soluciones que se iban encontrando en otros sistemas jurídicos; segundo, la industrialización, el desarrollo económico y una cierta internacionalización de

13 Sobre el origen y evolución del método comparado, entre otros, Constantinesco, J. L., Traité de droit comparé. Vol.I (Introduction au droit comparé), 1972; Hug, W., "The history of comparative law", Harvard Law Review, n 45, 1931/32, págs. 1027 y ss.; ZWEIGERT /KÖTZ, Introduction to comparative law, Clarendon Press, Oxford, 1998 ( $3^{\mathrm{a}}$ ed.), 48 y ss.

14 En su Política, ArIsTóteles escribe: «Puesto que nuestro propósito consiste en indagar cuál es entre todas las asociaciones políticas la que deberán preferir los hombres dueños de escoger una a su gusto, habremos de estudiar, a la vez, la organización de los Estados que pasan por ser los que tienen las mejores leyes y las constituciones imaginadas por los filósofos, limitándonos a las más notables; por este medio descubriremos lo que cada una de ellas puede encerrar de bueno y de aplicable, y al mismo tiempo demostraremos que si intentamos formas una combinación política diferente de todas, nos ha movido no un vano deseo de lucir nuestro ingenio, sino la necesidad de poner en claro los defectos mismos de todas las constituciones existentes", (Política, II, I). Anteriormente, Platón, en Las Leyes, hacía una comparación de las leyes de las Ciudades-Estado griegas, describiéndolas y contrastándolas con un modelo ideal que había deducido de todas ellas. 
la economía, que exigían una mayor actividad legislativa e impulsaron la comparación entre legisladores; y, tercero, el desarrollo de la escuela histórica, uno de cuyos elementos definitorios era el análisis histórico comparado. La consagración de la nueva ciencia se produjo ya iniciado el siglo xx y se sitúa en el conocido Congreso Internacional de Derecho Comparado, organizado por Raymond Saleilles y Édouard Lambert, celebrado en París los días 31 de julio a 4 de agosto de 1900, coincidiendo con la Exposición Universal. En dicho Congreso se sentaron las bases de la nueva disciplina, se definieron por primera vez sus criterios metodológicos, su objeto y su función, en un ambiente dominado por las ideas universalistas, la fe en el progreso, el convencimiento de que existían principios de general aplicación a todos los Estados e, incluso, que era posible unificar el derecho y crear un derecho universal. ${ }^{15} \mathrm{~A}$ estas características se sumó poco después otro elemento definitorio que ha determinado la concepción del derecho comparado hasta nuestros días; se trata del enfoque funcionalista, de acuerdo con el cual el análisis comparado no se guía por la norma o las instituciones jurídicas, sino por los problemas concretos a los que tiene que responder el derecho, es decir, sirve a la función de buscar soluciones jurídicas en el conjunto de los ordenamientos. ${ }^{16}$

Pues bien, esta ciencia del derecho comparado dio importantes frutos hasta mediados del siglo xx. ${ }^{17}$ Tras la Segunda Guerra Mundial, sin embargo, la creencia en las ideas universalistas se debilitó, sobre todo debido a la experiencia bélica de los años anteriores, lo cual supuso una cierta crisis en la ciencia del derecho comparado. Frente a la concepción inicial surgió una concepción más escéptica, se fijaron objetivos menos ambiciosos, se relativizaron las potencialidades del derecho comparado, se produjeron los correspondientes ajustes en el método, aunque el enfoque funcionalista siguió siendo el dominante, y, también, comenzaron a escucharse las primeras voces críticas con la autonomía científica de esta disciplina. ${ }^{18}$

En este punto hay que señalar que la mayoría de las aportaciones que contribuyeron al desarrollo de la ciencia del derecho comparado en la primera mitad del s. xx se produjeron en el ámbito del derecho privado. ${ }^{19}$ Este mayor empuje realizado por los ius privatistas se debió a que los factores que impulsaron el desarrollo de esta ciencia (la codificación, la industrialización y el desarrollo

15 Saleilles, R., "Conception et objet de la science juridique du droit comparé" y LamBert, E., "Conception générale et définition de la science du droit comparé", en Procèsverbaux des séances et documents, Congrès international de droit comparé 1900, LGDJ, Paris, 1905-1907, vol. I (1905). También se han recogido posteriormente en ZweIGERT/PUTTFARKEN (eds.), Rechtsvergleichung, Wissenschaftliche Buchgesellschaft, Darmstadt, 1978.

16 RaBel, E., Aufgabe und Notwendigkeit der Rechtsvergleichung, Hüber, München, 1925; y RHEInstein, M., Einfübrung in die Rechtsvergleichung, Beck, München, 1974.

17 La exposición histórica de esta etapa se puede consultar en ANCEL, M., Utilité et méthodes du droit comparé, Editions Ides et Calendes, Neuchatel, 1971, págs. 18 y ss.

18 Especialmente el trabajo ya citado de GuTTERIDGe, H. C., An introduction to the comparative method of legal study and research, op. cit. nota 2.

19 Como el conocido trabajo de LAMBert, E., La fonction du droit civil comparé, Giard, Paris, 1903. 
económico,...) afectaban especialmente al derecho privado, y no en la misma medida al derecho público. ${ }^{20}$ Así pues, el derecho privado fue el principal motor en la creación y desarrollo de la nueva disciplina, de tal modo que lo que aún hoy se considera teoría general del derecho comparado se gestó en el ámbito privado.

En cuanto al derecho constitucional, si bien el derecho público no desempeñó entonces un papel similar en relevancia al desempeñado por el derecho privado, no faltaron después aportaciones importantes en este ámbito, especialmente por parte de la doctrina italiana ${ }^{21}$ cuyos trabajos publicados a partir de mediados del siglo xx concluyeron señalando como rasgos de la "ciencia del derecho constitucional comparado" los siguientes:

- La autonomía del derecho constitucional comparado, a la que definen como "ciencia jurídica autónoma", "una de las ciencias jurídicas que tiene por objeto el estudio profundo de los ordenamientos constitucionales de los Estados, al lado de las ciencias del derecho constitucional particular, estimadas como las relativas a un único ordenamiento estatal, y la del derecho constitucional general, que constituye un capítulo específico de la teoría general del Derechom. ${ }^{22}$

- La especificidad del derecho constitucional comparado en el marco del derecho comparado general, especificidad que reside en que la comparación constitucional reviste características particulares que la distinguen sensiblemente de la comparación en el campo del derecho privado, ya que su objeto son las instituciones relativas a la organización del poder, y no las posiciones y relaciones jurídicas intersubjetivas de los individuos. ${ }^{23}$ De esa diferencia en cuanto al objeto derivan particularidades en la aplicación del método comparado, referidas a la actividad de aplicación del derecho, a la actividad de creación, modificación o derogación de normas, e, incluso, a la actividad investigadora y a la docente. ${ }^{24}$

- Las funciones del derecho constitucional comparado, que son una concreción de las funciones propias del derecho comparado general, y entre las que se incluyen: la adquisición de conocimiento, la verificación de datos, la comprensión del propio ordenamiento, la clasificación

20 Ancel, M., Utilité et méthodes du droit comparé, op. cit., pág. 15.

21 Las aportaciones han sido muy numerosas, entre ellas resulta obligado citar a: Rossi, L., Appunti di diritto pubblico comparato, Roma, 1935; Амовтн, A., Corso di diritto costituzionale comparato, Giuffrè, Milan, 1947; pero sobre todo las posteriores de BISCARETTI DI RuFIA, P., Introduzione al diritto costituzionale comparato, Giuffrè, Milan, 1970; De Vergottini, G., Diritto constituzionale comparato, Cedam, Padua, 1981; Pizzonusso, A., Sistemi giuridici comparati, Giuffrè, Milan, 1995; Morbidelli/ Pegoraro/ Reposo/ Volpi, Diritto pubblico comparato, Giappichelli, Turín, 2004, entre otros muchos.

22 BiscaretTI di Rufia, P., Introducción al derecho constitucional comparado, op. cit., pág. 13.

23 De Vergottini, G., Diritto costituzionale comparato, op. cit., pág. 2.

24 Pizzorusso, A., "La comparazione giuridica e il diritto pubblico”, en SACCO, R. (ed.), L' apporto della comparazione alla scienza giuridica, Giuffrè, Milan, 1980, págs. 59 a 83. 
y agrupación de los ordenamientos estatales, la interpretación de las normas constitucionales, la preparación de normas y la armonización normativa entre diferentes Estados. ${ }^{25}$

- La taxonomía propia del derecho constitucional comparado, ya que, de acuerdo con el método comparado general, el análisis de los diferentes ordenamientos se realiza clasificándolos y ordenándolos en diferentes categorías, familias o modelos teóricos. En este caso, las categorías determinantes para la clasificación son las conocidas "formas de Estado" y "formas de gobierno": Estados liberales, Estados socialistas, Estados autoritarios, Estados en vías de desarrollo..., sistemas parlamentarios, sistemas presidencialistas... La definición de estas categorías y el desarrollo de la teoría de las formas de Estado y las formas de gobierno han resultado determinantes para el derecho constitucional, y se han convertido, no sólo en criterio decisivo a tener en cuenta en el desarrollo de cualquier estudio comparado, sino también en pieza fundamental de la teoría del Estado constitucional. ${ }^{26}$

- La metodología, respecto a la cual no se advierten diferencias fundamentales con la del derecho privado comparado (elección de elementos comparables, análisis en el contexto,...), pero sí se reconoce y se insiste en la importancia del auxilio de otras ciencias y sus respectivos métodos: la ciencia política, la historia de las ideas, la historia constitucional, la economía..., que se han demostrado imprescindibles en las investigaciones de derecho constitucional comparado. ${ }^{27}$

Además de la aportación italiana, no podemos dejar de señalar que en Francia, Inglaterra y Estados Unidos también se han desarrollado trabajos sobre la ciencia del derecho constitucional comparado, aunque con la particularidad de que el método comparado no se considera allí un método estrictamente jurídico, porque incorpora elementos de otras ciencias (de la ciencia política, la historia o la economía), lo cual no es sino reflejo de la concepción que en estos países se tiene del derecho constitucional. Es decir, en estos países la ciencia del análisis comparado de las instituciones políticas es el resultado de una combinación de ciencia jurídica y ciencia política, con el apoyo de la historia y las ciencias económicas. ${ }^{28}$

Por último, parece obligado recordar las obras de derecho comparado publicadas en España, aunque, como se sabe, no permiten hablar de una ciencia española del derecho constitucional comparado y, además, se trata de obras

25 De Vergottini, G., Diritto costituzionale comparato, op. cit., págs. 4 y ss.

26 Es obligada la cita de los trabajos de MortaTI, C., Le forme di governo, Cedam, Padua, 1973; e Istituzioni di diritto pubblico, I, Cedam, Padua, 1975 ( $9^{\mathrm{a}}$ ed.), págs. 134 y ss.

27 Biscaretti di Rufia, P., Introducción al derecho constitucional comparado, op. cit., págs. 23 a 25; DE Vergottini, G., Diritto costituzionale comparato, op. cit., pág. 2.

28 Recordemos los conocidos trabajos de Burdeau, Duverger y Hauriou sobre "droit constitutionnel et institutions politiques. En el mismo sentido los trabajos anglosajones se refieren a ese tipo de análisis con expresiones como "comparative government and politics" y otras similares. 
que, en su mayor parte, han tenido por objeto el análisis y descripción de diferentes ordenamientos estatales, es decir, constituyen, no tanto trabajos de derecho comparado en sentido estricto, como exposiciones de derecho extranjero. ${ }^{29}$

\section{DERECHO CONSTITUCIONAL COMPARADO A PRINCIPIOS DEL S. XXI}

\section{La nueva Relevancia del Derecho constitucional comparado}

En materia constitucional, si bien es cierto que el recurso a la comparación ha sido siempre importante, hoy en día se ha convertido en herramienta imprescindible. A principios del siglo xxI el derecho público comparado ha cobrado una relevancia que no había tenido hasta ahora, y ello se debe, entre otros, a los siguientes motivos.

Para empezar, el recurso al método comparado se ha intensificado a medida que se constituían nuevos Estados constitucionales. A partir de la Segunda Guerra Mundial, y posteriormente desde la desintegración de la Unión Soviética, tanto en Europa como en otros ámbitos geo-políticos, cada vez son más los Estados constitucionales y, con ello, los actores ocupados en labores de redacción constitucional, interpretación y desarrollo de normas constitucionales.

Que el modo de organizar un nuevo sistema político constitucional guarde semejanzas con el de otros Estados constitucionales no puede sorprender hoy a nadie. Sin ir más lejos, nuestra Constitución se ha inspirado en el derecho constitucional de otros países; la jurisprudencia de nuestro Alto Tribunal se ha

29 En algunos manuales y tratados de la primera mitad del siglo xx se incluyó ya una parte dedicada al derecho comparado: así en el manual clásico de Posada, A., Tratado de Derecho Politico, Biblioteca de Derecho y de Ciencias Sociales, Madrid, 1928 ( $4^{\mathrm{a}} \mathrm{ed}$.), el tomo II está dedicado al derecho constitucional comparado; y Pérez SerRAno, N., Tratado de Derecho Político, Civitas, Madrid, publicado en 1976, aunque escrito entre 1936 y 1939, dedica nueve capítulos al derecho constitucional comparado (extranjero). Posteriormente, y hasta la aprobación de la Constitución de 1978, el contexto jurídico-político de la dictadura franquista justificó tanto el recurso al derecho comparado en la actividad investigadora y docente, como la ausencia de estudios de derecho comparado en sentido estricto en los que se incluyera el modelo español. De los trabajos de aquella época cabe citar los de Sevilla Andrés, D., Tratado de Derecho Constitucional (Legislación extranjera), ALDIA, Valencia, 1950 ( $2^{\mathrm{a}}$ ed.); SÁNCHEZ AGESTA, L., El derecho constitucional en Inglaterra, Estados Unidos, Francia, Portugal y la URSS, (s.n.), Granada, 1948; y, posteriormente, Curso de derecho constitucional comparado, Editora Nacional, Madrid, 1963; García Pelayo, M., Derecho Constitucional Comparado, Alianza, Madrid, 1950; JIMÉNEZ DE PARGA, M., Los regímenes políticos contemporáneos, Tecnos, Madrid, 1960. A pesar de la ruptura con la situación jurídico-política anterior que supuso la Constitución de 1978, los trabajos posteriores de derecho comparado han seguido siendo en su mayor parte exposiciones del régimen constitucional de otros sistemas políticos, como, por ejemplo, FerRando Badía, J. (coord..), Regímenes políticos actuales, Tecnos, Madrid, 1985; y SÁnchez González / Mellado Prado, Sistemas políticos actuales, Ed. Centro de Estudios Ramón Areces, Madrid, 1992; con la excepción del trabajo coordinado por LóPEz GarRIDO, Massó Garrote, Pegoraro, Nuevo derecho constitucional comparado, Tirant lo blanc, Valencia, 2000, que sigue el modelo de los manuales italianos en la materia. 
inspirado en buena medida, y va a continuar haciéndolo, en los trabajos anteriores de otros Tribunales Constitucionales con más años y experiencia; y en la elaboración de las leyes nuestros parlamentos se inspiran también en las legislaciones extranjeras. ${ }^{30} \mathrm{Y}$ eso mismo ocurre con cada uno de los nuevos Estados constitucionales.

Además, los ordenamientos jurídicos nacionales y las diferentes culturas constitucionales están siendo objeto de una creciente influencia recíproca, influencia que es el resultado de dos tipos de causas. En primer lugar, de causas ajenas al derecho, como los mejores conocimientos de idiomas, la creciente competencia en el campo de la investigación, la posibilidad de acceder por internet a fuentes extranjeras, y el aumento de las relaciones entre profesores, investigadores y jueces constitucionales de diferentes países. ${ }^{31}$ En segundo lugar, de ciertas causas jurídicas, entre las que destacan: la internacionalización cada vez mayor y más profunda de las condiciones de vida y de las condiciones económicas, la llamada mundialización o globalización; los crecientes vínculos internacionales entre Estados, como, por ejemplo, los existentes entre los miembros del Consejo de Europa firmantes del Convenio Europeo de Derechos Humanos; y la participación en procesos de integración supranacional, de la que es un excelente ejemplo la construcción de la Unión Europea. ${ }^{32}$

En el contexto de estos procesos de internacionalización y de integración, se está produciendo un doble efecto: de un lado, en el ámbito nacional se advierte una cierta homogeneización entre los diferentes derechos constitucionales nacionales, como consecuencia de la creciente influencia recíproca entre ordenamientos; de otro, en el plano supranacional, se manifiesta la necesidad de "constitucionalizar" de algún modo esos ámbitos internacionales que hoy determinan el desarrollo de los Estados, normalmente mediante la definición de los elementos constitucionales comunes a los Estados nacionales implicados. En ambos casos, como se puede adivinar, el elemento comparado juega un papel esencial.

Así, en el marco del Convenio Europeo de Derechos Humanos (CEDH), el Tribunal Europeo de Derechos Humanos (TEDH) ha venido desarrollado una detallada jurisprudencia sobre los derechos recogidos en el Convenio y, de ese modo, ha contribuido a incrementar los elementos constitucionales comunes europeos y a definir un "estándar» mínimo exigible en materia de derechos fundamentales. ${ }^{33}$ El Convenio ha servido de modelo a los catálogos de derechos de

30 Entre otros, Cascajo Castro, J. L., "Estudio introductorio", en Cascajo Castro/García ÁlvaREZ, Constituciones extranjeras contemporáneas, Tecnos, Madrid, 1994 (3 ed.), págs. 11 y ss. (págs. 51 y ss.).

31 Entre otros, Merli, F., "Hacia una Constitución común europea", en Revista de Derecho Comunitario Europeo, no 9, 2001, págs. 241 y ss.

32 Merli, F., "Hacia una Constitución ...", op. cit., págs. 247 y ss.; y López GuERRA, L., "Las constituciones europeas en el momento actual", Introducción a GómEz Orfanel, G., Las Constituciones de los Estados de la Unión Europea, CEC, Madrid, 1996.

33 FreIXEs, T., "Las principales construcciones jurisprudenciales del Tribunal Europeo de Derechos Humanos. El estándar mínimo exigible a los sistemas internos de derechos en Europa", en Cuadernos de la Cátedra Fadrique Furió Ceriol, n 11/12, 1995, págs. 9 a 115. 
muchas de las nuevas Constituciones, y, con carácter general, tal y como se establece en el art. 10.2 de la Constitución Española, las normas relativas a los derechos fundamentales de los Estados firmantes deben interpretarse conforme al $\mathrm{CEDH}$, de manera que, a través de la jurisprudencia vinculante del TEDH, se está produciendo un acercamiento, una cierta homogeneización, en materia de derechos fundamentales, entre todos los ordenamientos que participan en el Convenio. ${ }^{34}$ De otro lado, es preciso señalar que la jurisprudencia del TEDH no tiene un carácter absolutamente innovador, sino que responde a precedentes y doctrinas nacionales, que, a través de esa jurisprudencia, influyen y se integran en los ordenamientos jurídicos de los restantes miembros del Convenio. Como se ha demostrado al examinar el proceso de trabajo del TEDH, éste analiza los ordenamientos nacionales de los Estados firmantes, los compara, y trata de buscar el mayor número de coincidencias posibles, el "denominador común" de todos los ordenamientos nacionales, para definir así los elementos que utilizará en la fundamentación de sus decisiones. ${ }^{35}$

En este sentido hay que destacar que, en los actuales procesos de internacionalización e integración supranacional, resulta claro que los derechos fundamentales forman parte de esos elementos que necesariamente deben "constitucionalizar" los ámbitos internacionales en los que actúan los Estados. Por ello, uno de los objetos de estudio de derecho comparado que mayor atención despierta hoy son los sistemas de protección de derechos humanos. El contraste entre los niveles de protección de derechos fundamentales en los diversos ordenamientos nacionales e internacionales, y, con ello, el análisis comparado del reconocimiento, contenido y límites de dichos derechos está siendo materia de un elevado número de trabajos de investigación. ${ }^{36}$

En cuanto a la integración europea, ésta es, probablemente, el principal factor que hoy en día hace necesario el recurso al derecho comparado en nuestro entorno geo-político. Como consecuencia de dicha integración se está produciendo una importantísima influencia recíproca entre los sistemas constitucionales de los Estados miembros, un muy elevado grado de homogeneización entre ellos, y se está generando un "Derecho constitucional común europeon. ${ }^{37}$

La Unión Europea impone las mismas exigencias a todos los miembros y la integración produce consecuencias de orden constitucional muy similares en to-

34 Por todos, WaLTER, Ch., "Die Europäische Menschenrechtskonvention als Konstitutionalisierungsprozess", Zeitschrift für ausländisches öffentliches Recht und Völkerrecht, 1999, págs. 961-983.

35 Por todos, Grabenwarter, Ch., Europäische Menschenrechtskonvention, Beck, München, 2003, pág. 48; GANSHOF VAN DE MEERSCH, W. J., "La référence au droit interne des états contractants dans la jurisprudence de la Cour européenne des droits de l'homme,, Revue internationale de droit comparé, 1980. Vid también los trabajos recogidos en Blackburn/ Polakiewicz, Fundamental Rights in Europe, Oxford University Press, Oxford, 2001.

36 CoING, H., "Aufgaben der Rechtsvergleichung in unserer Zeit", Neue Juristische Wochenschrift, 1981.

37 Especiamente, HäBerLE, P., "El Derecho Constitucional común europeo", en Revista de Estudios Políticos, n 79, 1993, págs. 7 y ss. 
dos ellos. Recordemos, por ejemplo, que de acuerdo con el art. 6 del Tratado de la Unión Europea, los principios de libertad, democracia, respeto a los derechos humanos y libertades fundamentales, y el principio del Estado de derecho, se consideran comunes a todos los Estados miembros, y que, conforme a las disposiciones introducidas por el Tratado de Amsterdam, la incorporación de nuevos miembros va unida al cumplimiento de esos principios, amén de que se podrán suspender los derechos que corresponden a un Estado como miembro de la Unión Europea en el caso de violación de los mencionados principios. Pero más significativo aún es el apartado 2 del artículo 6, que establece que la Unión Europea respetará los derechos fundamentales tal y como se garantizan en el $\mathrm{CEDH}$, y tal y como resultan de las tradiciones constitucionales comunes a los Estados miembros. Pues bien, la definición de ese acervo común de tradiciones constitucionales exige, sin duda alguna, el recurso al estudio comparado de los derechos constitucionales nacionales. ${ }^{38} \mathrm{Y}$ no es éste el único caso en el que los Tratados remiten a los "principios comunes a los Estados miembros", 39 ni lo será, ya que, del mismo modo, el futuro de la construcción europea, sin avanzamos por el camino de la integración política, vendrá determinado por la cultura constitucional común de los Estados que participen en ella. ${ }^{40}$

Y, en fin, como se sabe, para la consecución de sus objetivos, la Unión Europea pretende la armonización normativa entre los ordenamientos de los Estados miembros en muy diversas materias, es decir, la reducción o supresión del mayor número de diferencias posibles entre las correspondientes normativas. Pues bien, con carácter general, el procedimiento para conseguirlo consiste en el

38 Así lo demuestra la jurisprudencia del Tribunal de Justicia de las Comunidades. El Tribunal, desde la Sentencia en el caso Stauder (STJCE de 12 de noviembre de 1969), ha reconocido a los derechos humanos como principios generales del derecho comunitario (principios comunes a los ordenamientos de los Estados miembros), concepto al que el Tribunal ha recurrido en aquellas ocasiones en las que los Tratados no le ofrecían suficientes elementos para resolver un problema. Para definir esos principios, es obvio que el Tribunal ha acudido al análisis de los ordenamientos de los Estados miembros, análisis que normalmente no se reproduce en el texto de la correspondiente sentencia, pero cuyas conclusiones sí forman parte del razonamiento que se realiza en la misma. Por ejemplo, en la Sentencia del caso Hauer (STJCE de 13 de diciembre de 1979), relativa al derecho de propiedad, el Tribunal recurre a las normas y a la praxis constitucional de nueve Estados miembros. También es cierto que por regla general el Tribunal de Justicia se ha apoyado en la jurisprudencia del TEDH en lugar de acudir directamente a los ordenamientos nacionales.

39 Por ejemplo, en materia de responsabilidad extracontractual de las instituciones (art. 288 TCE). En otras materias el Tribunal también ha tenido que recurrir a las "tradiciones constitucionales comunes" para resolver un recurso; por ejemplo, en la Sentencia del Caso Denkavit italiana (STJCE de 27 de marzo de 1980), el Tribunal compara los sistemas nacionales de tutela jurisdiccional en materia de restitución de impuestos indebidamente percibidos.

40 Merli, F., "Hacia una Constitución común europea”, op. cit., págs. 249 y ss. En este sentido son cada vez más numerosos los estudios de derecho comparado que analizan el reconocimiento y desarrollo de los principios constitucionales básicos en los diferentes Estados miembros de la Unión Europea. Por ejemplo, Hofmann/ Höllander/ Merli/ Wiederin (ed.), Armut und Verfassung, Verlag Österreich, Viena, 1998, sobre el principio del Estado social; Hofmann/ Marko/ MerLI/ WIEDERIN (eds.), Information, Medien und Demokratie, Verlag Österreich, Viena, 1997, sobre el Estado democrático; y, de los mismos, Rechtsstaatlichkeit in Europa, Verlag Österreich, Viena, 1996, sobre el principio del Estado de derecho. 
análisis comparado de las legislaciones nacionales con objeto de deducir una norma de referencia. Esa norma se construye: primero, incorporando los elementos comunes de las leyes nacionales; y, segundo, en cuanto a las diferencias entre ellas, bien se incluye la variante que se considera mejor, bien se elabora una solución nueva. En cualquier caso, los trabajos preparatorios de derecho comparado son absolutamente imprescindibles. ${ }^{41}$ En materia constitucional, por ejemplo, las leyes nacionales sobre protección de datos personales, desarrollo de un derecho fundamental, son transposición de la correspondiente directiva europea, elaborada a partir del estudio de las diferentes normativas nacionales. ${ }^{42}$ Pues bien, esta función auxiliar que el derecho comparado realiza en la elaboración de textos normativos ha adquirido hoy una enorme relevancia, no sólo en el caso de la armonización comunitaria, sino en la redacción de todo tipo de tratados y documentos internacionales. ${ }^{43}$

\section{LA REAPERTURA DEL DEBATE SOBRE LA CIENCIA DEL DERECHO COMPARADO}

Una vez advertida la importancia que ha adquirido el derecho constitucional comparado en las actuales coordenadas de internacionalización e integración europea, es preciso señalar las consecuencias que de ello derivan para la concepción de la disciplina, ya que la nueva relevancia que ésta ha adquirido ha reavivado el debate que se inició a mediados del siglo xx sobre la naturaleza y el método del derecho comparado.

Algunos de los factores que determinaron el nacimiento de la ciencia del derecho comparado en el siglo XIX (el movimiento codificador, la industrialización y el desarrollo económico...), guardan cierta similitud con los factores que hoy hacen imprescindible el recurso a la comparación (los procesos de armonización normativa en la Unión Europea, la globalización económica...). La actual tendencia a la homogeneización normativa conecta con los ideales de universalidad y de construcción de un derecho común mundial conforme a los cuales se definió la ciencia del derecho comparado a principios del siglo pasado. Por ello es lógico que hoy se haya producido una recuperación del derecho comparado tradicional con las características a las que ya hemos hecho referencia anteriormente: enfoque funcionalista, ideas universalistas, clasificaciones en familias legales...

Pero la recuperación de la versión tradicional del derecho comparado ha supuesto recuperar también, como es obvio, las críticas que a mediados del siglo xx

41 La bibliografía sobre ese fenómeno moderno de comparación en el contexto de la integración europea es extensa, entre otros cabe citar: HARDING/ ÖRÜcü, Comparative Law in the 21st Century, Kluwer, Londres, 2002; MARKesinIs, B., Foreign law and comparative methodology: a subject and a thesis, Hart, Oxford, 1997.

42 Vid. Arenas Ramiro, M., El derecho fundamental a la protección de datos personales en Europa, Tirant lo blanch, Valencia, 2006.

43 Sobre esta función auxiliar del derecho constitucional comparado, De VergottinI, G., Diritto costituzionale comparato, Cedam, Padua, 2004 ( $6^{\mathrm{a}} \mathrm{ed}$.), vol. I, págs. 20 a 23; ZweIGERT /KÖTZ, An introduction to comparative law, op. cit., págs. 24 y ss. 
se le hicieron a ésta. A partir de ellas han surgido hoy en día concepciones alternativas del derecho comparado que tienen en común ciertos rasgos críticos: cuestionan las posibilidades y límites del derecho comparado y de la unificación normativa debido a las diferencias irreconciliables entre sistemas jurídicos; consideran que cada ordenamiento jurídico responde a un contexto político, económico, cultural y moral, y que no hay un denominador común que haga posible elaborar conceptos neutrales y objetivos; por ello mismo entienden que no es posible aplicar soluciones jurídicas de un ordenamiento jurídico a otro; advierten que el estudioso del derecho comparado está condicionado por su contexto cultural y su ordenamiento jurídico, que se acerca a los ordenamientos extranjeros lleno de "prejuicios", con una "precomprensión" de los mismos, lo cual le impide ser imparcial; y, por todo lo anterior, consideran que las categorías y clasificaciones típicas del derecho comparado tradicional son subjetivas, arbitrarias y no representativas; incluso, critican la "ideología" a la que responde la tradicional ciencia del derecho comparado, la de un proyecto hegemónico de unificación siguiendo un determinado modelo, y, de acuerdo con ello, consideran que los procesos de armonización normativa son una forma de intervensionismo político. ${ }^{44}$

A nuestro juicio, si relativizamos algunas de las críticas más exageradas, las nuevas concepciones del derecho comparado constituyen una aportación valiosa para el desarrollo de dicha ciencia. En principio, parten de un reconocimiento del pluralismo y destacan la importancia de atender a las diferencias de todo tipo que existen entre sistemas jurídicos, así como la necesidad de integrar diferentes perspectivas. En segundo término, recuerdan la relación estrecha que existe entre un análisis de derecho comparado y el contexto social y político, por lo que insisten en la necesidad de adoptar un enfoque interdisciplinar y lo más comprensivo posible. Y, en tercer lugar, subrayan el potencial crítico de los estudios de derecho comparado, porque, más allá de la posibilidad de encontrar soluciones legales en otros ordenamientos (enfoque funcionalista), muestran que la verdadera utilidad de este tipo de análisis reside en que son una herramienta idónea para desarrollar un conocimiento crítico: colocan al investigador en un contexto diferente, le ofrecen perspectivas distintas, otros conceptos y razonamientos, y le permiten adoptar la distancia intelectual necesaria para volverse con ojos críticos al propio ordenamiento. ${ }^{45}$

Teniendo en cuenta estas aportaciones críticas a la concepción clásica del derecho comparado, y en el actual contexto de internacionalización, nos permitimos apuntar varias indicaciones que pueden resultar útiles para cualquier estudio de derecho comparado.

44 La bibliografía es muy extensa, se puede citar al trabajo de referencia de FranKERBERG, G., "Critical comparations: re-thinking Comparative law", Harvard International Law Journal, $\mathrm{n}^{\circ}$ 26, 1985, págs. 411 y ss.; así como las contribuciones de D. Kennedy, G. Frankerberg, N. Berman, entre otros, al Congreso "New approaches to comparative law", publicadas en la Utah Law Review, 1997; además, Grosswald, V., "Cultural inmersión, difference and categories in US Comparative Law", American Journal of Comparative Law, no 43, 1998, págs. 50 y ss.

45 Vid., en este sentido, el excelente trabajo de A. PeTters y H. SCHWEnKE, "Comparative law beyond post-modernism", en International and Comparative Law Quarterly, n 49, 2000, págs. 800 y ss. 
- Así, en primer lugar, si bien es cierto que se han incrementado los elementos políticos, jurídicos y económicos comunes entre los Estados europeos, también es cierto que las diferencias entre ordenamientos nacionales y culturas constitucionales aún existen y deben seguir siendo tenidas en cuenta. Por ello, en el actual proceso de constitucionalización europea se insiste en que, junto a la necesaria armonización constitucional, se debe garantizar el pluralismo, el mantenimiento de la identidad constitucional de los Estados miembros, así como los espacios constitucionales propios que permiten a las comunidades nacionales reconocerse como tales. ${ }^{46}$

- En segundo lugar, los ordenamientos que hay que tomar en consideración en un estudio de derecho comparado ya no son solamente los ordenamientos nacionales, sino también los supranacionales. En Europa, por ejemplo, un estudio de ese tipo exige analizar los ordenamientos nacionales de los Estados europeos, el ordenamiento comunitario y, en su caso, otros ordenamientos sectoriales de carácter internacional, como es, en materia de derechos fundamentales, el Convenio Europeo de Derechos Humanos. ${ }^{47}$

- En tercer lugar, y desde el punto de vista de los ordenamientos nacionales, dependiendo siempre de la materia de que se trate y de la perspectiva que se quiera adoptar, interesa el análisis comparado con los restantes Estados de la Unión Europea, por las razones que hemos visto. Pero también interesa el análisis de los Estados Unidos, referente indiscutible en el mundo globalizado en el que hoy vivimos y cuya influencia se advierte tanto en materia de derechos fundamentales - ya que la interpretación que el Tribunal Supremo de aquel país ha hecho de determinados derechos ha influido en la jurisprudencia del Tribunal Europeo de Derechos Humanos y, a través de ésta, en la de los Tribunales Constitucionales nacionales- como en materia de organización del Estado - por ejemplo, en la creación de las autoridades reguladoras que en la mayoría de los países europeos se encargan hoy de supervisar los sectores económicos liberalizados-. Y, finalmente, en el contexto de la creciente homogeneización que se experimenta en el ámbito europeo, interesan los sistemas jurídicos que ofrecen perspectivas diferentes, como pueden ser los ordenamientos latinoamericanos, debido a que en ellos se están desarrollando procesos de tendencia contraria a la europea; así, por ejemplo, mientras en Europa hemos sufrido la transformación de nuestro "Estado gestor" en "Estado regulador", de la mano de los conocidos procesos de privatizaciones y de liberali-

46 Sobre esta exigencia, entre otros, Cruz Villalón, P., La Constitución inédita. Estudios ante la constitucionalización de Europa, Trotta, Madrid, 2004, pág. 149.

47 Así lo reconocen los últimos manuales de la materia, como la última edición de DE VERGotTin, G., Diritto costituzionale comparato, 2004 ( $6^{\mathrm{a}}$ ed.), págs. 24 y 25, que advierte cómo el objeto del derecho constitucional comparado no son ya únicamente los ordenamientos nacionales sino cada vez más éstos y los ordenamientos internacionales. 
zación de sectores públicos, en el denominado "cono sur" se están desarrollando procesos inversos, del "Estado regulador", que se organizó en aquellos países bajo el auspicio de determinadas organizaciones internacionales, hacia un nuevo "Estado gestor", mediante la reorganización de determinados sectores en los que el Estado se reserva ciertas formas de intervención como garantía de la prestación de bienes y servicios. ${ }^{48}$

\section{ACTUALES INFLUENCIAS RECÍPROCAS ENTRE DIFERENTES CULTURAS CONSTITUCIONALES}

Por último, nos gustaría concluir estas reflexiones sobre el derecho comparado de nuestros días deteniéndonos en el examen de las actuales influencias recíprocas entre diferentes ordenamientos jurídicos a las que ya hemos hecho referencia.

Esas influencias se perciben muy claramente al observar las principales características de los sistemas jurídicos tradicionales y sus transformaciones más recientes (se trata, en todo caso, de observaciones muy generales, ya que un análisis profundo de las mismas excede el objetivo de este trabajo). Para ello hemos tomado como referencia la clásica distinción entre las familias del common law y las del derecho romano-germánico (civil law), que siempre han mostrado grandes diferencias entre sí, por lo que los cambios producidos en ellas en los últimos años, de tendencia contraria a la que les es característica, resultan especialmente demostrativos del actual proceso de influencias recíprocas. ${ }^{49}$

\section{1. "RIGIDIFICACIÓN" DE LOS SISTEMAS DE COMMON LAW}

En el caso de los sistemas de common law, que tradicionalmente se han definido por su flexibilidad, se observan rasgos de signo contrario, es decir, de "rigidificación", característicos de los sistemas continentales.

El sistema jurídico inglés ha sido el modelo de los denominados sistemas de common law, que se han mostrado siempre como conceptualmente con-

48 Ese es, por ejemplo, el caso de Uruguay, cuya Constitución se reformó hace dos años para incorporar un derecho fundamental al agua de los ciudadanos, que obliga al Estado a desempeñar un papel central en la garantía del mismo y a que la gestión de este bien sea total o parcialmente pública. En este sentido, C. de Cabo Martín en su intervención en la Jornada sobre Orientación y Método del Derecho Constitucional, cuyas actas se publican este mismo número.

49 En el periodo de entreguerras las clasificaciones clásicas realizadas en los trabajos generales de derecho comparado (en el ámbito del derecho privado) se centraban en esta distinción. Ello fue debido a que los intentos de unificación del derecho, objetivo entonces del derecho comparado, se encontraron con la existencia de diferencias irreconciliables entre los dos grupos de sistemas jurídicos que integran las familias del "common lau" y el "civil lau". 
trapuestos a los sistemas jurídicos romano-germánicos o continentales ("sistemas de civil lawn), sobre todo por lo que se refiere a la concepción del derecho y el sistema de fuentes.

La evolución histórico-política, diferente en el continente y en el Reino Unido, ha condicionado las correspondientes concepciones del Derecho. En éste último se ha generado un sistema jurídico de naturaleza jurisprudencial con una historia multisecular, en el que el Derecho no se concibe como un sistema ordenado de normas que se deducen de unos principios universales, sino que se desarrolla dialécticamente, en un proceso inacabado que perdura en la historia, y conforme a las reglas del proceso judicial. El Derecho surge de la inducción a partir de la experiencia empírica y de las circunstancias del caso concreto ( $i u$ ris prudentia); el derecho no se crea (law-making), sino que se encuentra, se declara y se aplica (law-declaring)..$^{50}$

Por lo que a la Constitución se refiere, la Norma Suprema británica también es diferente de las Constituciones continentales contemporáneas. Es "el arquetipo de las constituciones flexibles" (de las que se reforman por el mismo órgano y siguiendo el mismo procedimiento que la ley ordinaria) y "la más acabada expresión positiva del concepto histórico de constitución, pues es un desarrollo de decisiones parciales que se extienden desde la Carta Magna hasta nuestros días, y de usos y costumbres formados lentamente y sin fecha de nacimiento precisa ${ }^{51}$ Además, las fuentes del Derecho constitucional (el statute law -el derecho escrito-, el case law - el derecho judicial-, los usos y costumbres,...) no difieren sustancialmente de las fuentes de otras ramas del Derecho público, ni de las del Derecho privado, y entre ellas no existe una relación jerárquica clara, aunque el derecho judicial ocupa una posición preeminente. ${ }^{52}$

Pues bien, desde la perspectiva de la concepción del derecho y el sistema de fuentes, en las últimas décadas el sistema inglés se ha aproximado a los sistemas continentales. Por ejemplo, la actividad legislativa en el Reino Unido se ha intensificado, se aprueban muchas más normas escritas que anteriormente, y la ley -el statute law- se ha convertido, como en el continente, en la fuente principal del derecho. El derecho judicial, aunque ya no es la fuente primaria, ocupa todavía un lugar destacado, más relevante que el que le corresponde en los sistemas continentales, pero se ha transformado también al

50 Por ejemplo, vid. Kriele, M., Introducción a la Teoría del Estado, De Palma, Buenos Aires, 1980, pág. 195; y, del mismo, Theorie der Rechtsgewinnung, Duncker \& Hublot, Berlin, 1976 (2 ${ }^{\mathrm{a}}$ ed.), págs. 60 y ss. Aunque sobre la concepción del derecho en los sistemas de common law se puede consultar una extensa bibliografía, empezando por los tratados y manuales de derecho comparado.

51 García Pelayo, M., Derecho Constitucional Comparado, op. cit., págs. 276-277 y págs. 285 y ss.

52 En el ámbito del derecho constitucional, por ejemplo, BradLey \& EwIn, Constitutional and administrative law, Longman, Londres, 2003 (13 ${ }^{\mathrm{a}}$ ed.), págs. 12 y ss. Entre nosotros, Pereira Menaut, A., El ejemplo constitucional de Inglaterra, Servicio de publicaciones de la Facultad de Derecho UCM, Madrid, 1992, págs. 5 a12. 
asumir la interpretación de la ley. ${ }^{53}$ Estos cambios se han producido en el contexto de internacionalización e integración europea que ya hemos referido. Como en el resto de los Estados miembros de la Unión Europea, un gran número de las normas escritas que se aprueban hoy en el Reino Unido traen causa del derecho comunitario, son transposición de directivas comunitarios o se aprueban para satisfacer las correspondientes exigencias de la integración. Y, en el ámbito del Consejo de Europa, el Convenio Europeo de Derechos Humanos ha obligado al Reino Unido a aprobar una norma escrita en la que se reconociesen los principales derechos fundamentales, la Human Rights Act, lo cual, como se sabe, ha supuesto una verdadera revolución constitucional en aquel país. ${ }^{54}$

Desde el punto de vista de la organización del Estado, las transformaciones más importantes han afectado al Parlamento. Como se sabe, el sistema parlamentario británico se desarrolló en una situación histórico-política diferente de la del continente, aunque las diferencias con los sistemas parlamentarios continentales no son sustanciales. Únicamente hay que recordar que el Parlamento se considera la más alta institución del Reino Unido y que, en consecuencia, no existe un sistema de control de constitucionalidad de la ley como el continental. Pues bien, el principio de la "soberanía del Parlamento", que constituye uno de los pilares de la arquitectura constitucional de aquel país, está siendo sometido a revisión. De un lado, la integración del Reino Unido en la Unión Europea, con las consecuencias que ello ha traído consigo, sobre todo por lo que al principio de primacía del Derecho comunitario se refiere, ha obligado a reinterpretar dicho principio, aunque la práctica ha demostrado la dificultad de compatibilizar "la soberanía del Parlamento británico" con "la primacía del derecho comunitarion. ${ }^{55}$ De otro lado, la participación del Reino Unido en el Convenio Europeo de Derechos Humanos ha supuesto el sometimiento de los actos de los poderes públicos (incluido el Parlamento) al control del Tribunal Europeo de Derechos Humanos, y, desde la aprobación de la Human Rights Act, el sometimiento de las leyes al control de los tribunales nacionales, encargados de juzgar la "compatibilidad" de las mismas con la $H u$ man Right Act y con el Convenio, aunque, para respetar formalmente el principio de "soberanía del parlamento", los tribunales no declaran la

53 Vid. Barendt, E., An Introduction to Constitutional Law, Oxford University Press, Oxford, 1998, pág. 69; y un buen resumen de la discusión doctrinal inglesa sobre el tema en McELDOwnEY, J. F., Public Law, Sweet \& Maxwell, Londres, 1999 (2ª ed.), págs. 213 y ss.

54 Entre otros, McEldowney, J. F., Public Law, Sweet \& Maxwell, Londres, 2002 (3 ${ }^{\mathrm{a}}$ ed.), págs. 54 a 56; Craig, P., "Britain in the European Union", en Jowell / Oliver, The Changing Constitution, Clarendon Press, Oxford, 2004 ( $5^{a}$ ed.), págs. 88 y ss. Entre nosotros, Sánchez GonZÁlez, S., “Cambios constitucionales en el Reino Unido de la Gran Bretaña", Teoria y Realidad Constitucional, ${ }^{\circ}$ 1, 1998, págs. 215-222; y “Cambios constitucionales en el Reino Unido de la Gran Bretaña II", Teoría y Realidad Constitucional, no 5, 2000, págs. 253-256.

55 Sobre la modificación del principio de la soberanía del Parlamento como consecuencia de la integración del Reino Unido en la Unión Europea, vid. BARENDT, E., An Introduction to Constitutional Law, op. cit., pág. 69; Bradley \& Ewing, Constitucional and Administrative Law, op. cit., págs. 135 y ss. 
«inconstitucionalidad" de la ley, sino la incompatibilidad, que, además, debe resolver el propio Parlamento. ${ }^{56}$

\section{2. «FLEXIBILIZACIÓN» DE LOS SISTEMAS CONTINENTALES}

En el caso de los sistemas continentales, por el contrario, se observan nuevos rasgos característicos de la flexibilidad propia de los sistemas de common law.

Los sistemas jurídicos continentales de tradición romano-germánica, como ya hemos señalado, responden a otra concepción del derecho, disponen de una Constitución escrita y rígida, y de un sistema de control de constitucionalidad concentrado. Desde la aparición del Estado moderno, el Derecho, o más concretamente la norma jurídica, se concibe como expresión de la voluntad soberana y manifestación de la idea de Justicia $;{ }^{57}$ se concibe como un conjunto complejo de normas, a las que se llega mediante la deducción a partir de grandes principios racionales de validez universal y atemporal (scientia iuris), que forman un sistema, ordenado, de acuerdo con diferentes categorías y subcategorías, y completo, es decir, capaz de dar respuesta a todos los casos que se presenten..$^{58}$

Pues bien, en los últimos tiempo se han observado ciertos cambios relativos a la estructura misma de ese derecho. El "conjunto completo y ordenado de normas jurídicas" se ha abierto a principios, convenciones, recomendaciones, normas de autorregulación, códigos de conducta..., formas de expresión de la voluntad, distintas de la norma jurídica en sentido estricto, provenientes de los órganos del Estado, de organismos internacionales, y de los propios privados, que han adquirido una fuerza vinculante de la que anteriormente carecían en los sistemas jurídicos continentales y que, sin embargo, sí era característica de los sistemas de common law. Esta transformación es a la que Zagrebelski se ha referido al afirmar que nuestro derecho tiende a convertirse en un diritto mite (derecho dúctil), un derecho en el que la norma-regla se sustituye por la norma-principio, un derecho de principios propio de las sociedades pluralistas actuales. ${ }^{59}$ Haciendo referencia a este mismo fenómeno, otros advierten del avan-

56 Bamforth, N., "Parliamentary sovereignty and the Human Rights Act 1998", en Public Law, 1998, winter, págs. 572 y ss.; y Bradley, A., "The Sovereignty of Parliament —Form or substance?", en Jowell / Oliver, The Changing Constitution, Clarendon Press, Oxford, 2004 ( $5^{\mathrm{a}}$ ed.), págs. 26 y ss.

57 García Pelayo, M., en el apartado sobre la idea medieval del Derecho en el trabajo "Del mito y la razón en el pensamiento político", recogido ahora en las Obras Completas, CEC, Madrid, tomo II, 1991; también von HayeK, F. A., Recht, Gesetzgebung und Freibeit, Verl. Mod. Ind., Landsberg am Lech, vol. 2, 1986 ( $2^{\text {a }}$ ed.), págs. 105 y ss.

58 Sobre la concepción continental, KrIEle, M., Introducción a la Teoría del Estado, op. cit., págs. 146 a 147; Alusson, J., A Continental Distinction in the Common Law, Oxford University Press, Oxford, 1996, pág. 35.

59 Zagrebelsky, G., Il diritto mite. Legge, diritti, giustizia, 1992; traducido como El derecho dúctil, Trotta, Madrid, 1995. 
ce de lo que los internacionalistas llaman el soft law, un derecho en el que la norma se transforma en recomendación o invitación, y del que existen numerosísimos ejemplos en el Derecho Comunitario. Recomendaciones, comunicaciones, programas, informes, dictámenes y otros documentos de trabajo no son vinculantes para los Estados miembros, no se trata de actos normativos típicos, son instrumentos carentes también a priori de fuerza obligatoria, aunque no de efectos jurídicos, ya que sirven, por ejemplo, como parámetro de interpretación del hard law o para atenuar la responsabilidad que pudiera derivarse de la infracción de éste. ${ }^{60}$

En el plano de la organización del Estado, la mayor influencia extraña a nuestro modelo organizativo se produce en el ámbito de la administración. De un lado, las agencias, autoridades independientes y otros organismos similares, propios de la tradición anglosajona, han comenzado a aparecer en la mayoría de los Estados de la Europa continental. ${ }^{61}$ De otro, numerosas iniciativas relativas al control de la administración, a la gestión eficiente de los servicios públicos, etc..., que responden igualmente al modelo flexible de administración descentralizada británica, están comenzando a proponerse también en los ordenamientos continentales. ${ }^{62}$ Prueba de ello son, por ejemplo, los "contratos programa" a través de los cuales se financian ahora ciertos organismos públicos, "la externacionalización de servicios", o los mecanismos de "autoevaluación" y de control interno en organismos públicos.

ABSTRACT. This paper analyses the actual features of comparative constitutional law. First of all it examines the nature, object and method of comparative law, as well as its origins and historical development. Then, it focuses on the new relevance of comparative constitutional law as a consequence of internationalisation and European integration processes, and on the mutual influences among different legal systems and different constitutional cultures.

60 Alonso García, R., "El soft law comunitario", Revista de Administración Pública, n 154 , 2001, págs. 63 y ss.; in extenso, Senden, L., Soft Law in European Community Law, Hart, Oxford, 2004.

61 Salvador Martínez, M., Autoridades independientes. Un análisis comparado de los Estados Unidos, el Reino Unido, Alemania, Francia y España, Ariel, Barcelona, 2002.

62 Entre los referentes británicos se pueden citar, entre otros, la Financial Management Initiative (FMI) de los años ochenta, a través del cual se introdujeron en la administración los principios de gestión, la forma de trabajo y los instrumentos de control coste-beneficio propios de la empresa privada; y, en el mismo sentido, el proyecto de New Public Management (NPM), de los años noventa, que pretendía la transformación de la estructura administrativa tradicional y de su forma de trabajo, para lo cual incluía la incorporación de especialistas en gestión pública, el establecimiento de estándares vinculantes, controles de resultados, reducción de las grandes estructuras administrativas, y la introducción de competencia entre organismos públicos, entre otras propuestas. 